\title{
Research on the Characteristics of Microscopic Damage to Different Pore Types by Slippery Water Fracturing Fluid in the Chang Member Tight Sandstone Reservoir, Ordos Basin, NW China
}

\author{
Aojiang Qi $\mathbb{D}^{1},{ }^{1}$ Pinshu Qian, ${ }^{2}$ Hai Huang, ${ }^{1}$ Dazhong Ren ${ }^{D},{ }^{1}$ Xiaoyu Gu, ${ }^{1}$ Fan Zhang, $^{1}$ \\ and Xun Yuan ${ }^{3}$ \\ ${ }^{1}$ Shaanxi Key Laboratory of Advanced Stimulation Technology for Oil \& Gas Reservoirs, Xi'an Shiyou University, \\ Xi'an 710065, China \\ ${ }^{2}$ Research Institute of Petroleum Exploration \& Development, Langfang 065000, China \\ ${ }^{3}$ PetroChina Kunlun Gas Co., Ltd., Zhongning Branch, Zhongning 755100, China \\ Correspondence should be addressed to Aojiang Qi; ajqi@xsyu.edu.cn
}

Received 13 November 2020; Revised 30 November 2020; Accepted 15 December 2020; Published 6 January 2021

Academic Editor: Chun Zhu

Copyright () 2021 Aojiang Qi et al. This is an open access article distributed under the Creative Commons Attribution License, which permits unrestricted use, distribution, and reproduction in any medium, provided the original work is properly cited.

\begin{abstract}
This paper examines the damage caused by slickwater fracturing fluid to the microscopic pore structure of tight sandstone in the Chang 7 member in the Ordos Basin. A submicron CT in situ displacement system was used to analyze and graphically represent changes in pores in core samples following fracturing fluid damage. The results show the following: (1) the damage caused by slickwater fracturing fluid to tight sandstone fractures mainly occurs in the early stage of fluid incursion. The damage is characterized by a decrease in the effective pore volume, increase in the number of pores, and insignificant subsequent damage. The main causes of pore damage by slickwater fracturing fluid are retention of slickwater in the liquid phase and hydration swelling of clay minerals in the pores. (2) After the high pressure intrusion of slickwater fluid, the pore size of largesize intergranular pores increases, and there is no obvious damage after water flooding. However, fractures and small dissolution pores in the cores are the main areas of fluid retention after fracturing fluid invasion due to their small flowing radius and complex structure. These are the locations where damage mostly occurs.
\end{abstract}

\section{Introduction}

There are enormous resource reserves in tight sandstone reservoirs in China. With conventional oil and gas resources decreasing year on year, this type of reservoir has become an important replacement resource for current petroleum industry development $[1,2]$. Due to the extremely low permeability of rocks in this type of reservoir, volume fracturing of horizontal wells with slickwater is the primary method for industrial development [3]. Currently, volume fracturing in horizontal wells generally adopts the operation mode of "thousands of cubic meters of sand, tens of thousands of cubic meters of fracturing fluid." The volume of fracturing fluid injected into horizontal wells is much higher than that into ordinary vertical wells. Reduction in the permeability of reservoir rock and corresponding impact on the production of oil wells is inevitable once a reservoir has been invaded by slickwater fracturing fluid [4-6].

Evaluation of the degree of damage cause by fracturing fluid to reservoir rocks has generally been based on the measurement of the permeability of core samples. Due to the strong heterogeneity of extremely low porosity structures in tight sandstones, macroscopic core experiments tend to encounter a number of problems such as large differences in experimental results, poor quantification, and difficult in visualization. It is therefore difficult to quantitatively characterize the damage caused to rock pores by fracturing fluid invasion at different time intervals [7-10]. A more accurate 


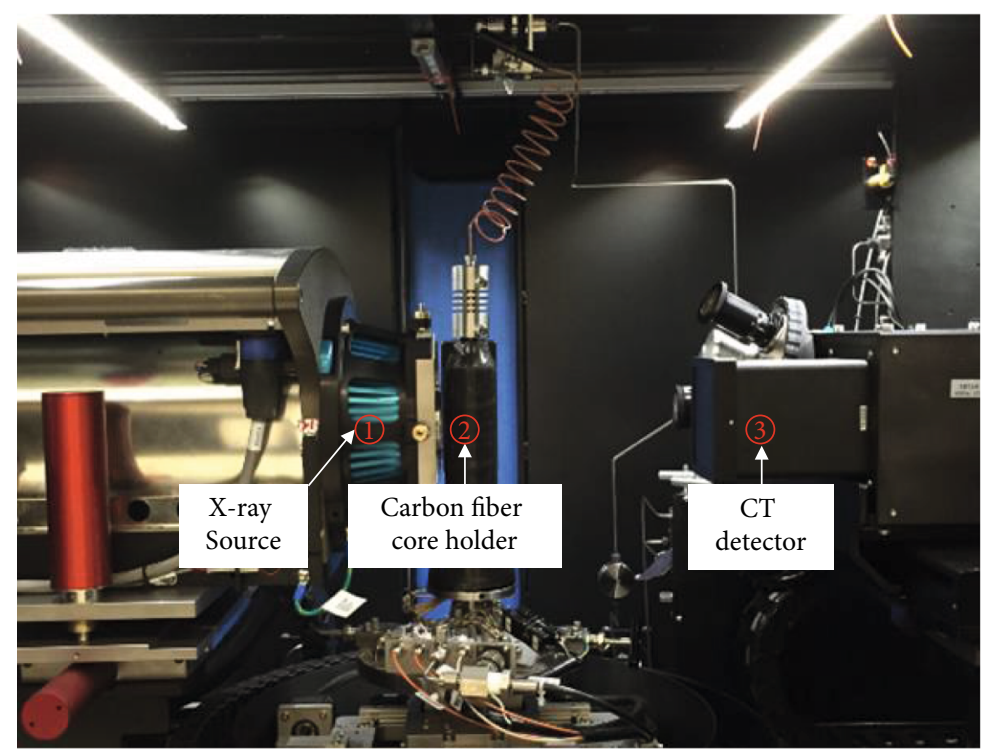

Figure 1: Experimental setup.

experimental method is urgently required to fully understand the microscopic characteristics of slickwater fracturing fluid incursion and its relationship to pore-scale damage in tight sandstones [11]. In recent years, with continuous improvement of the accuracy of CT (Computed Tomography) scanning, it has become possible to explore pore phenomena in tight sandstone at a submicron scale [12-14]. Highprecision Computed Tomography has the characteristics of intuitive quantification, visualization, and nondestructiveness, the technology, so it has been increasingly applied in the field of microscale research in petroleum engineering [15-19]. Currently, this technology is mostly used for quantitative characterization of the pore structures of lowpermeability cores and determination of the characteristics of oil-water displacement and seepage. There have been few studies on the microscopic characteristics of slickwater damage to pores in tight low-permeability sandstones, despite the need to deepen the understanding of this process [20-32].

This paper takes the tight sandstone of Chang 7 Member in the Ordos Basin as the research object. A ZEISS highprecision CT in situ displacement system was used to carry out microscopic examination of fracturing fluid damage in a core from the Chang 7 member. With the pore volume expansion ratio as the evaluation index, a quantitative visualization study was conducted to determine the characteristics of damage caused by invasion of slickwater fracturing fluid to various types of pores-such as fractures, intergranular pores, and micropores-using high-precision original scan grayscale images. The research results provide a crucial experimental basis for deepening understanding of the microscopic characteristics of damage caused by incursion of slickwater fracturing fluid in tight sandstone reservoirs and later EOR.

\section{Experimental Methods and Samples}

2.1. Experimental Core Data. For this study, a core from the tight oil reservoir of the Chang 7 Member in the northern part of the Ordos Basin in Shaanxi Province was selected for sealed coring. The core had an air permeability of 0.408 $\times 10^{-3} \mu \mathrm{m}^{2}$ and a porosity of $8.86 \%$.

\subsection{Principal Experimental Instruments and Materials}

(1) Main instruments: Zeiss submicron CT (510 VERSA), in situ displacement system (including temperature control system), CT scanning carbon fiber core holder are used as the main instruments. The experimental device is shown in Figure 1

(2) Main materials: core from the Chang 7 Member and formation water (salinity $95300 \mathrm{mg} / \mathrm{L}$, water type $\mathrm{CaCl}_{2}$ ) containing EM30S type slickwater filtrate (Table 1) are the main materials used.

2.3. Experimental Methods. Since the pore size of tight sandstone is mostly micron or below submicron, radial displacement of over $1 \mathrm{~mm}$ or rotation or tilt of more than 1 degree of the rock sample during the scanning process will cause difficulty in accurately comparing the core sample's pores before and after CT scanning

The in situ displacement system used for this study effectively avoids this problem and is capable of obtaining highquality data. The specific experimental steps are as follows:

(1) CT scanning of core samples after saturation with formation water:

(i) Step 1: a core section with a diameter of $10 \mathrm{~mm}$ and length of $30 \mathrm{~mm}$ is placed in a carbon fiber core holder and fixed on the CT scanning stage.

(ii) Step 2: the ambient temperature of the holder is set at $45^{\circ} \mathrm{C}$, and the confining pressure at $20 \mathrm{MPa}$. The 
TABLE 1: Slickwater fracturing fluid formula and filtrate parameters.

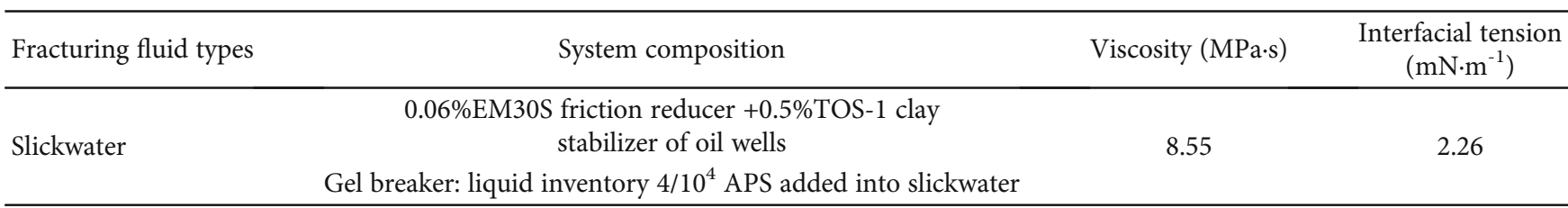

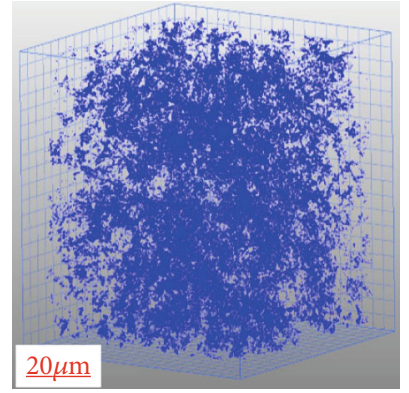

(a)

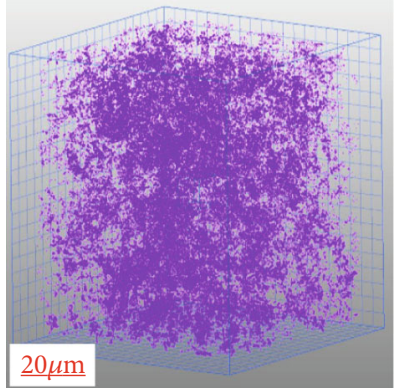

(b)

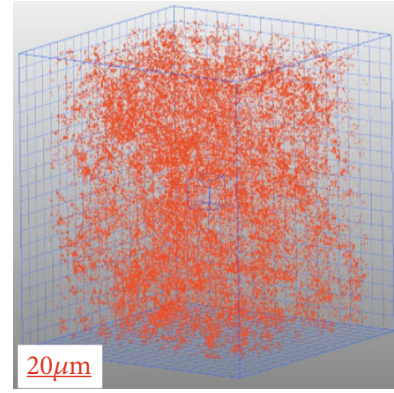

(c)

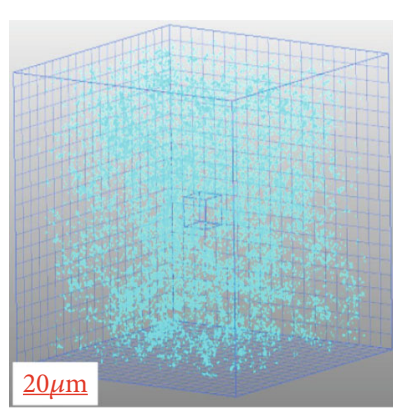

(d)

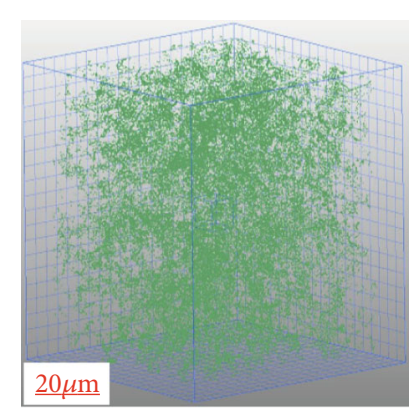

(e)

FIGURE 2: Variations in the pore volume of cores at different times (Note: (a) snapshot after saturation with formation water; (b) $9 \mathrm{~h}$ after fracturing fluid invasion; (c) $24 \mathrm{~h}$ after fracturing fluid invasion; (d) $72 \mathrm{~h}$ after fracturing fluid invasion; (e) $24 \mathrm{~h}$ after subsequent water flooding).

vacuum pump of the displacement system is turned on, then stopped after 8 hours.

(iii) Step 3: the microinjection pump and the inlet valve are opened. After $12 \mathrm{~h}$ of saturation with formation water, the pump is stopped and the inlet valve is closed.

(iv) Step 4: the system is set as follows: the scanning voltage is $70 \mathrm{KV}$, the power is $5 \mathrm{~W}$, the power of the objective lens is $4 \mathrm{x}$, and resolution is $1.03 \mu \mathrm{m}$. Image scanning is initiated to obtain graphic information of the pore structure of each slabbed core.

(2) CT scanning is carried out at different time intervals after fracturing fluid invasion:

(i) Step 1: the microinjection pump and the inlet valve are opened to force the slickwater fracturing fluid filtrate into the core. The pump is stopped after $9 \mathrm{~h}$, and the inlet valve is closed.
TABLE 2: Statistics of pore volume and number of pores in the core at different times.

\begin{tabular}{lcc}
\hline Sample status & $\begin{array}{c}\text { Number of } \\
\text { pores }\end{array}$ & $\begin{array}{c}\text { Total pore volume } \\
\left(\mu \mathrm{m}^{3}\right)\end{array}$ \\
\hline $\begin{array}{l}\text { Saturated formation water } \\
9 \mathrm{~h} \text { after fracturing fluid } \\
\text { invasion }\end{array}$ & 77193 & 594370 \\
$\begin{array}{l}24 \mathrm{~h} \text { after fracturing fluid } \\
\text { invasion }\end{array}$ & 117164 & 427345 \\
$\begin{array}{l}72 \mathrm{~h} \text { after fracturing fluid } \\
\text { invasion }\end{array}$ & 116054 & 410365 \\
$\begin{array}{l}24 \mathrm{~h} \text { after formation water } \\
\text { flooding }\end{array}$ & 110650 & 405365 \\
\hline
\end{tabular}

(ii) Step 2: graphic information of the pore structure of cores after $9 \mathrm{~h}$ of fracturing fluid invasion is obtained with the system settings as above.

(iii) Step 3: graphic information of the pore structure of cores after is obtained after $24 \mathrm{~h}$ and again after $72 \mathrm{~h}$ of fracturing fluid invasion, essentially by repeating step 2 . 


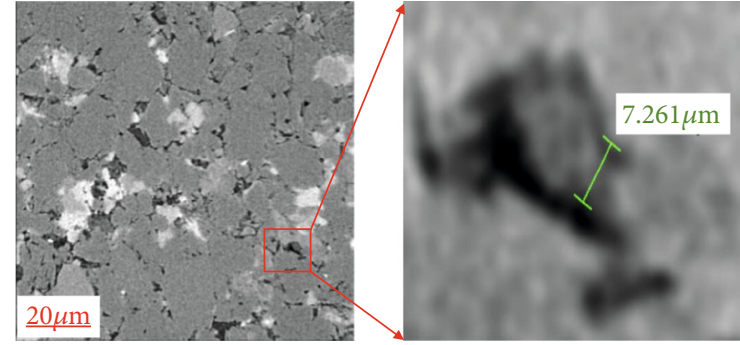

(a)

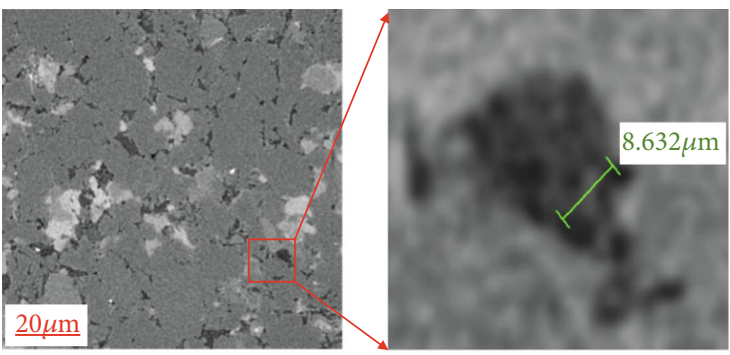

(c)

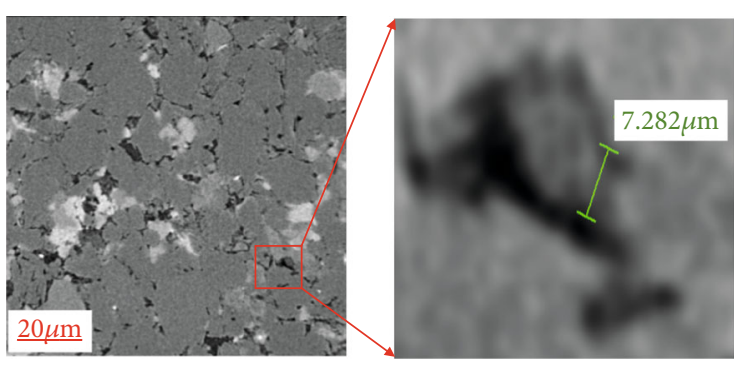

(e)

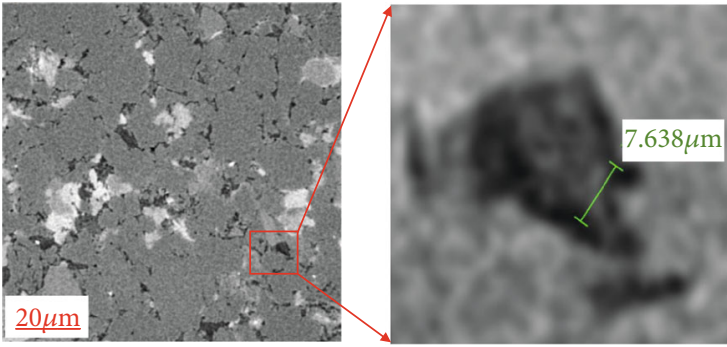

(b)

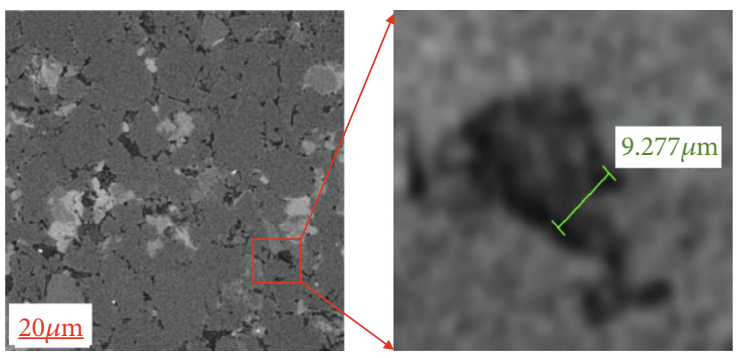

(d)

FIGURE 3: Characteristics of mineral size changes of typical intergranular pores at different stages (Note: (a) snapshot following saturation with formation water; (b) $9 \mathrm{~h}$ after fracturing fluid invasion; (c) $24 \mathrm{~h}$ after fracturing fluid invasion; (d) $72 \mathrm{~h}$ after fracturing fluid invasion; (e) $24 \mathrm{~h}$ after subsequent water flooding).

TABLE 3: Changes of typical intergranular pore size over time.

\begin{tabular}{|c|c|c|c|}
\hline State & Pore diameter $(\mu \mathrm{m})$ & Expansion ratio (\%) & Gray value of intergranular pore \\
\hline Saturated formation water & 7.261 & - & 4536 \\
\hline $9 \mathrm{~h}$ after fracturing fluid invasion & 7.638 & 5.19 & 4853 \\
\hline $24 \mathrm{~h}$ after fracturing fluid invasion & 8.632 & 18.88 & 5240 \\
\hline $72 \mathrm{~h}$ after fracturing fluid invasion & 9.277 & 27.77 & 5760 \\
\hline $24 \mathrm{~h}$ after formation water flooding & 7.282 & 2.96 & 4570 \\
\hline
\end{tabular}

(3) CT scanning after subsequent formation water injection: the microinjection pump and the inlet valve are opened, with the pump being stopped after 10PV formation water has been injected. After $24 \mathrm{~h}$, the system is again set as above to obtain a graphical "snapshot" of the pore structure of the core at that moment.

(4) CT scan data processing:

(i) Step 1: the pore volume of the core is extracted using the Otsu algorithm. (ii) Step 2: changes in pore diameters before and after fracturing fluid invasion are obtained by calculating pixel points.

\section{Results and Discussion}

3.1. Influence of Fracturing Fluid Intrusion on the Total Pore Volume of Cores. Based on the experimental procedure set out in 2.2 supra, the CT scan images obtained at $9 \mathrm{~h}, 24 \mathrm{~h}$, and $72 \mathrm{~h}$ after saturation with formation water, fracturing fluid invasion, and subsequent water flooding were systematically compared. The number of pores and the characteristics 


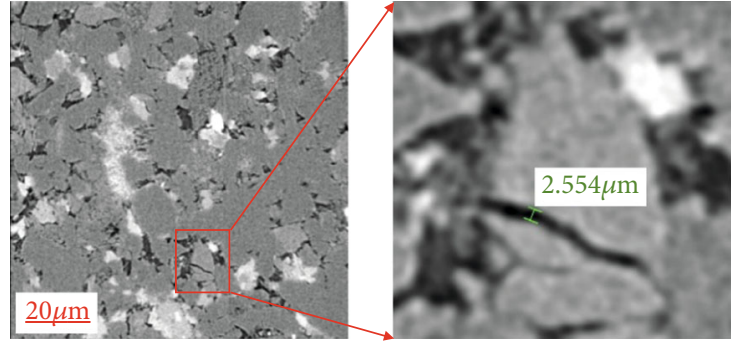

(a)

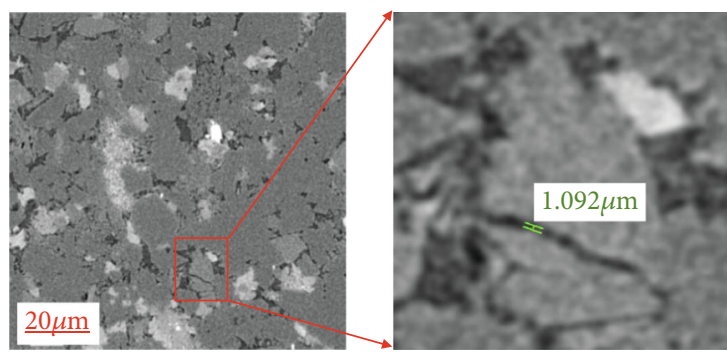

(c)

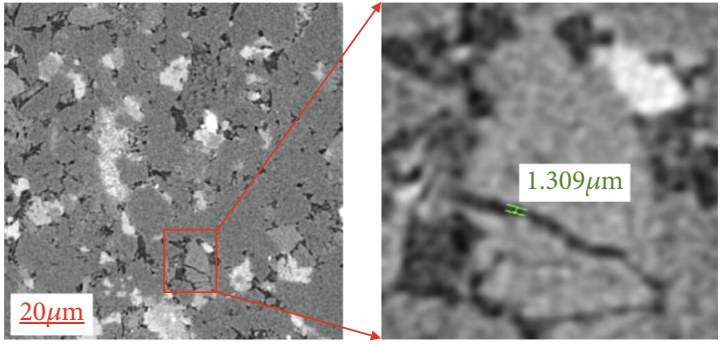

(b)

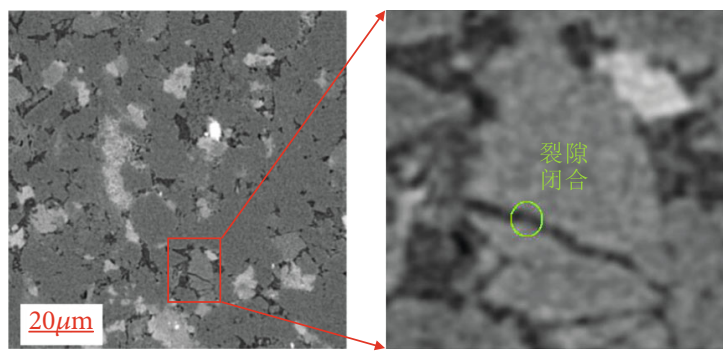

(d)

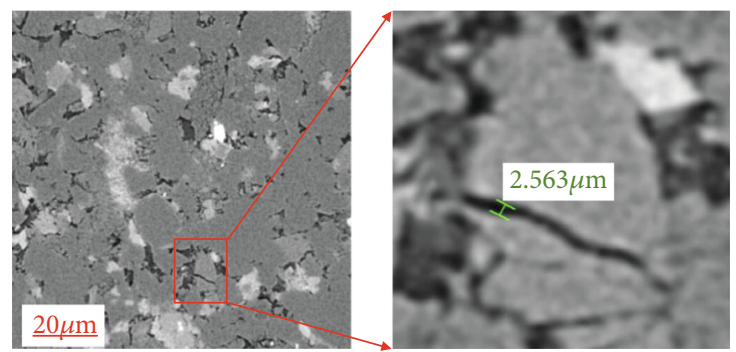

(e)

FIgURE 4: Changes in the degree of openness of typical pores and fractures at different times (Note: (a) snapshot following initial saturation with formation water; (b) $9 \mathrm{~h}$ after fracturing fluid invasion; (c) $24 \mathrm{~h}$ after fracturing fluid invasion; (d) $72 \mathrm{~h}$ after fracturing fluid invasion; (e) $24 \mathrm{~h}$ after subsequent water flooding).

of volume changes in the core at different times are shown in Figure 2 and Table 2.

Figure 2 and Table 2 show the following: first, the number of pores in tight sandstone initially increases with fracturing fluid invasion and then stabilizes; second, the pore volume of tight sandstone initially decreases and then stabilizes with fracturing fluid invasion, and the volume decrease mainly occurs in the early stage of fracturing fluid invasion; third, after fracturing fluid invasion and subsequent water flooding, the total pore volume was partially restored but struggled to return to its original state. After slickwater fracturing fluid invasion, the damage rate to the pore volume of the tight sandstone was about $21.13 \%$.

Analysis indicates that the main cause of this phenomenon is that, under the condition of high pressure immersion in fracturing fluid, some weakly cemented rock particles are dispersed, resulting in an increase in the number of pores. However, pores plugged by fracturing fluid invasion, together with the hydration and expansion of clay minerals, lead to an overall decrease in total pore volume.

3.2. Influence of Fracturing Fluid Invasion on Intergranular Pores in the Core. Second, the intergranular pores in the experimental core samples were analyzed. The effects of fracturing fluid damage on the pores and fractures of cores at different times were compared. A representative intergranular pore with obvious characteristics was selected from the scan data as the analysis object, and the results are shown in Figure 3 and Table 3.

Figure 3 and Table 3 show that intergranular pore diameters increase after fracturing fluid filtrate invasion under high pressure. At an interval of $72 \mathrm{~h}$ after saturation with the fracturing fluid, the size of the studied pore had increased from $14.521 \mu \mathrm{m}$ to $18.554 \mu \mathrm{m}$, an increase of $27.77 \%$. After subsequent water flooding, this type of pore can return to its original size, indicating that high-pressure invasion of fracturing fluid has the effect of expanding intergranular pores but does not cause significant damage to this type of pore.

3.3. Influence of Fracturing Fluid Invasion on Fractures in the Core. To clarify the damage that the fracturing fluid caused to different types of pores in the core, fractures in the experimental core samples were studied to compare the impact of fracturing fluid on the fractures in the cores at different time intervals. A representative fracture with obvious 
TABLE 4: Variation of fracture width changes over time.

\begin{tabular}{lccc}
\hline State & Openness degree $(\mu \mathrm{m})$ & Rate of change of openness degree (\%) & Image; gray in the fracture area \\
\hline Saturated formation water & 2.554 & - & 5338 \\
$9 \mathrm{~h}$ after fracturing fluid invasion & 1.309 & 48.77 & 6139 \\
$24 \mathrm{~h}$ after fracturing fluid invasion & 1.092 & 57.24 & 6671 \\
$72 \mathrm{~h}$ after fracturing fluid invasion & 0 & 100.00 & 7952 \\
$24 \mathrm{~h}$ after formation water flooding & 2.5625 & - & 5449 \\
\hline
\end{tabular}

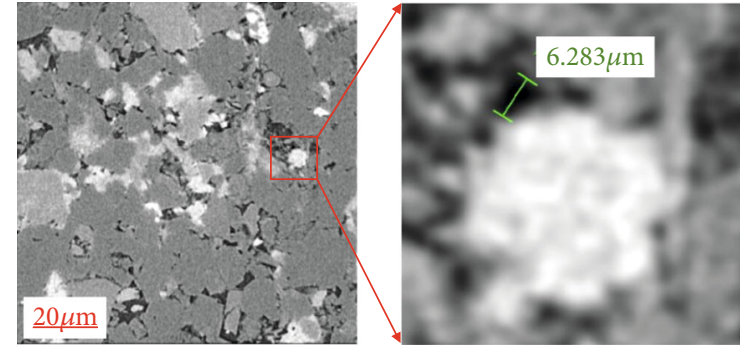

(a)

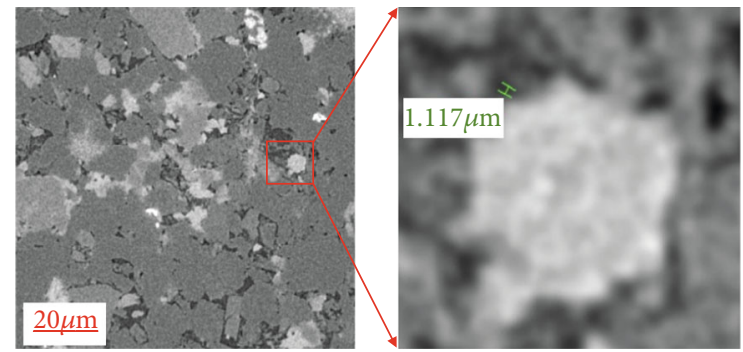

(c)

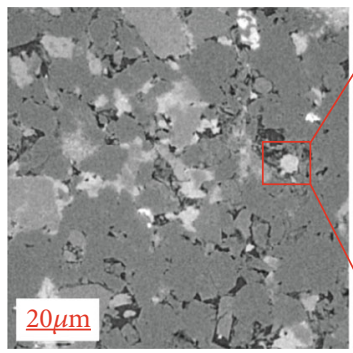

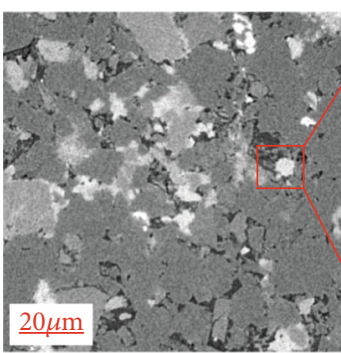

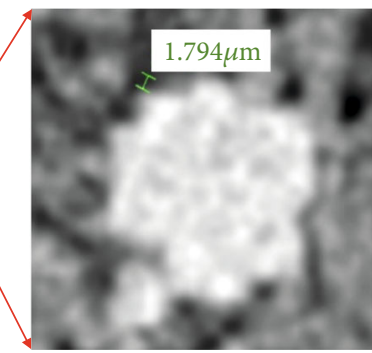

(b)
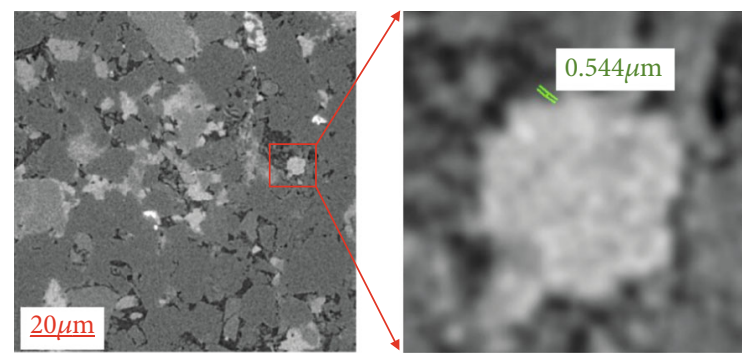

(d)

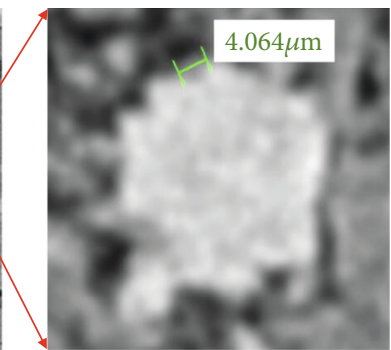

(e)

FIGURE 5: Size changes of typical micropores in different stages (Note: (a) snapshot following saturation with formation water; (b) $9 \mathrm{~h}$ after fracturing fluid invasion; (c) $24 \mathrm{~h}$ after fracturing fluid invasion; (d) $72 \mathrm{~h}$ after fracturing fluid invasion; (e) $24 \mathrm{~h}$ after subsequent water flooding).

characteristics was selected from the scan data as the analysis object, and the results are shown in Figure 4 and Table 4.

It can be seen from Figure 4 and Table 4 that the width of pores and fractures increases with the invasion time of fracturing fluid and that the gray value of the image increases. This indicates that the intrusion volume of fracturing fluid increases, resulting in a continuous decrease in the effective openness degree of fractures. After saturation by fracturing fluid for $72 \mathrm{~h}$, the fractures at the measuring point tend to be closed. However, after subsequent water flooding, the gray values of the fractures continue to decrease. This indicates that the invading fracturing fluid filtrate has been discharged and that the gray value can be restored to the same value as at the moment of saturation with formation water. This suggests that, although slickwater fracturing fluid causes considerable damage to the pores and fractures of tight rocks, the damage can be greatly reduced by subsequent water flooding.

3.4. Impact of Fracturing Fluid Invasion on Dissolved Pores in the Core. Finally, the dissolved pores in the experimental core samples were analyzed to compare the influence of fracturing fluid on the dissolved pores in the cores at different times. A representative fracture with obvious characteristics was selected from the scan data as the analysis object and the results are shown in Figure 5 and Table 5. 
TABLE 5: Changes of micropore size over time.

\begin{tabular}{lccc}
\hline Time $(\mathrm{h})$ & $\begin{array}{c}\text { Size } \\
(\mu \mathrm{m})\end{array}$ & $\begin{array}{c}\text { Rate of change } \\
(\%)\end{array}$ & $\begin{array}{c}\text { Gray } \\
\text { value }\end{array}$ \\
\hline $\begin{array}{l}\text { Saturated formation water } \\
\text { 9 h after fracturing fluid } \\
\text { invasion }\end{array}$ & 6.283 & - & 8245 \\
$\begin{array}{l}\text { 24h after fracturing fluid } \\
\text { invasion }\end{array}$ & 1.794 & 71.45 & 7335 \\
$\begin{array}{l}\text { 72 h after fracturing fluid } \\
\text { invasion }\end{array}$ & 0.544 & 91.34 & 6952 \\
$\begin{array}{l}\text { 24h after formation water } \\
\text { flooding }\end{array}$ & 4.064 & 35.32 & 7863 \\
\hline
\end{tabular}

It can be seen from Figure 4 and Table 4 that the diameters of dissolved pores in the core decrease constantly with slickwater fracturing fluid invasion. The minerals expand rapidly between 0 and 24 hours of saturation, but the mineral swelling tends to be gentle between 24 and 72 hours after saturation. The pore diameter is reduced from $12.566 \mu \mathrm{m}$ to $1.088 \mu \mathrm{m} 72 \mathrm{~h}$ after saturation-a reduction of $91 \%$. The change in gray value shows that, after subsequent water flooding, the invading fracturing fluid in intergranular pores is discharged. Therefore, although the effective pore diameter is increased, the initial level is not easily recovered, indicating that, for dissolved pores with greater percolation resistance and smaller pore diameter, fracturing fluid is more likely to be retained. This is the principal factor that causes reservoir damage.

\section{Conclusions}

(1) Damage to tight sandstone fractures caused by slickwater fracturing fluid mainly occurs in the early stage of fluid incursion. The damage is characterized by a decrease in the effective pore volume, increase in the number of pores, and insignificant later damage. The principal cause of damage caused to pores in core samples by slickwater fracturing fluid is retention of slickwater in the liquid phase and hydration swelling of clay minerals in the pores

(2) After high pressure intrusion of slickwater fluid, the pore size of large-size intergranular pores increases, and there is no obvious damage after water flooding. However, fractures and small dissolution pores in the cores are the primary areas of fluid retention after fracturing fluid invasion due to their small flowing radius and complex structure. It is here that core damage occurs

\section{Data Availability}

Data is available. If you need data, please contact the author.

\section{Conflicts of Interest}

The authors declare no conflicts of interest.

\section{Acknowledgments}

This research was financially supported by Open Fund of Shaanxi Key Laboratory of Advanced Stimulation Technology for Oil \& Gas Reservoirs (grant number 20JS120); Young Science and Technology Talents Foundation of Shaanxi province (grant number 2019KJXX-054); and National Natural Science Foundation of China (grant numbers 41702146, 51934005, and 51874242).

\section{References}

[1] X. Gu, C. Pu, N. Khan, F. Wu, F. Huang, and H. Xu, "The visual and quantitative study of remaining oil microoccurrence caused by spontaneous imbibition in extra-low permeability sandstone using computed tomography," Fuel, vol. 237, pp. 152-162, 2019.

[2] X. GU, C. PU, H. HUANG et al., "Micro-influencing mechanism of permeability on spontaneous imbibition recovery for tight sandstone reservoirs," Petroleum Exploration and Development, vol. 44, no. 6, pp. 1003-1009, 2017.

[3] Z. D. Sun, C. Z. Jia, and X. F. Li, Unconventional Oil \& Gas Exploration and Development, Petroleum Industry Press, Beijing, China, 2011.

[4] Z. Sun, H. Zhang, Z. Wei et al., "Effects of slick water fracturing fluid on pore structure and adsorption characteristics of shale reservoir rocks," Journal of Natural Gas Science and Engineering, vol. 51, pp. 27-36, 2018.

[5] D. Zhang and T. Yang, "Environmental impacts of hydraulic fracturing in shale gas development in the United States," Petroleum Exploration and Development, vol. 42, no. 6, pp. 876-883, 2015.

[6] Q. Lei, B. Guan, B. Cai et al., "Technological progress and prospects of reservoir stimulation," Petroleum Exploration and Development, vol. 46, no. 3, pp. 605-613, 2019.

[7] X. Feng, X. Peng, L. Li et al., "Influence of reservoir heterogeneity on water invasion differentiation in carbonate gas reservoirs," Natural Gas Industry B, vol. 38, no. 6, pp. 67-75, 2018.

[8] Y. Al-Khulaifi, Q. Lin, M. J. Blunt, and B. Bijeljic, "Reservoircondition pore-scale imaging of dolomite reaction with supercritical $\mathrm{CO}_{2}$ acidified brine: effect of pore-structure on reaction rate using velocity distribution analysis," International Journal of Greenhouse Gas Control, vol. 68, pp. 99-111, 2018.

[9] D. Hussein, J. Lawrence, F. Rashid, P. Glover, and P. Lorinczi, "Developing pore size distribution models in heterogeneous carbonates using especially nuclear magnetic resonance," in Engineering in Chalk, pp. 529-534, London, UK, 2018.

[10] R. M. Sok, M. A. Knackstedt, T. Varslot, A. Ghous, S. Latham, and A. P. Sheppard, "Pore scale characterization of carbonates at multiple scales: integration of Micro-CT, BSEM, and FIBSEM," Petrophysics, vol. 51, no. 6, pp. 1-12, 2010.

[11] J. Li, Y. Liu, Y. Gao, B. Cheng, F. Meng, and H. Xu, "Effects of microscopic pore structure heterogeneity on the distribution and morphology of remaining oil," Petroleum Exploration and Development, vol. 45, no. 6, pp. 1112-1122, 2018.

[12] S. Iglauer, A. Paluszny, and M. J. Blunt, "Simultaneous oil recovery and residual gas storage: a pore-level analysis using in situ x-ray micro-tomography," Fuel, vol. 103, pp. 905-914, 2013.

[13] S. Iglauer, M. A. Fernø, P. Shearing, and M. J. Blunt, "Comparison of residual oil cluster size distribution, morphology and 
saturation in oil-wet and water-wet sandstone," Journal of Colloid and Interface Science, vol. 375, no. 1, pp. 187-192, 2012.

[14] S. H. Zhang, Y. M. Chen, J. Hou, and X. L. Shi, "Image processing for CT microscopic coreflooding experiments," Petroleum Geology \& Oilfield Development in Daqing, vol. 26, no. 1, pp. 10-12, 2007.

[15] Z. Xinwei and X. Hong, "Microfocus X-CT based fine characterization of carbonate pore texture," Special Oil and Gas Reservoir, vol. 23, no. 1, pp. 127-131, 2016.

[16] G. M. Wu, X. Li, S. S. Gao, and W. G. An, "Optimal thresholding in carbonate reservoir CT image binarization based on fractal theory," Oil Geophysical Prospecting, vol. 52, no. 5, pp. 1025-1032, 2017.

[17] S. Y. Xie, Z. L. He, Y. X. Qian et al., "Multifractality of 3D pore structures of carbonate rocks based on CT images," Journal of Geology, vol. 39, no. 1, pp. 46-53, 2015.

[18] X. Wang, Z. Shen, D. Zhang, H. U. Shuo, B. Zhang, and X. Zhang, "Microscopic pore structure characteristics after ASP flooding based on CT scanning technique of the fulldiameter core," Petroleum Geology \& Oilfield Development in Daqing, vol. 38, no. 2, pp. 81-86, 2019.

[19] J. Gao, P. Liu, H. M. Liu, and J. Lv, "Study of carbonate core porosity distribution features using X-Ray CT," West-China Exploration Engineering, vol. 22, no. 4, pp. 36-39, 2010.

[20] T. Zhang, J. Shou, X. Zheng, S. Min, and L. Pan, "Spatial distribution and characterization of pore and throat of oolitic dolostone of the Lower Triassic Feixianguan Formation in northeastern Sichuan Province," Journal of Palaeogeography, vol. 14, no. 2, pp. 187-196, 2012.

[21] Z. H. Jianfeng, C. H. Yongquan, and N. I. Xinfeng, "Microstructure characterization based on CT imaging technology of Cambrian dolomite reservoir in Tarim Basin," Natural Gas Geoscience, vol. 27, no. 5, pp. 780-789, 2016.

[22] B. Bin, Z. Rukai, W. Songtao, C. Jingwei, S. Ling, and L. Tingting, "New micro-throatstructural characterization techniques for unconventional tight hydrocarbon reservoir," China Petroleum Exploration, vol. 19, no. 3, pp. 78-86, 2014.

[23] J. Yuqiang, C. Lin, J. Chan et al., "Characterization techniques and trends of the pore structure of tight reservoir," Geological Science and Technology Information, vol. 33, no. 3, pp. 63-70, 2014.

[24] K. Jiao, S. Yao, H. Wu, M. Li, and Z. Tang, "Advances in characterization of pore system of gas shales," Geological Journal of China Universities, vol. 20, no. 1, pp. 151-161, 2014.

[25] B. Bai, R. Zhu, S. Wu et al., "Multi-scale method of nano (micro)-CT study on microscopic pore structure of tight sandstone of Yanchang Formation, Ordos Basin," Petroleum Exploration and Development, vol. 40, no. 3, pp. 329-333, 2013.

[26] D. Rong, S. Luo, L. Qiqi, and X. Wei, "Porethroat distribution and flow characteristics of tight sandstone in Sulige Gasfield," Geological Science and Technology Information, vol. 36, no. 3, pp. 144-149, 2017.

[27] W. Sun, C. E. Shi, J. Z. Zhao, and L. Zhao, “Application of XCT scanned image technique in the research of micro-pore texture and percolation mechanism in ultar-premeable oil field," Acta Geologica Sinica, vol. 80, no. 5, pp. 775-779, 2006.

[28] X. Zhang, Y. Wu, E. Zhai, and P. Ye, "Coupling analysis of the heat-water dynamics and frozen depth in a seasonally frozen zone," Journal of Hydrology, no. article 125603, 2020.
[29] X. Wang, C. Liu, S. Chen, L. Chen, K. Li, and N. Liu, "Impact of coal sector's de-capacity policy on coal price," Applied Energy, vol. 265, p. 114802, 2020.

[30] C. Zhu, M. C. He, M. Karakus, X. B. Cui, and Z. G. Tao, "Investigating toppling failure mechanism of anti-dip layered slope due to excavation by physical modelling," Rock Mechanics and Rock Engineering, vol. 53, no. 11, pp. 5029-5050, 2020.

[31] C. Zhu, X. Xu, W. Liu et al., "Softening damage analysis of gypsum rock with water immersion time based on laboratory experiment," IEEE Access, vol. 7, pp. 125575-125585, 2019.

[32] H. Y. Pan, D. W. Yin, N. Jiang, and Z. G. Xia, "Crack initiation behaviors of granite specimens containing crossing-doubleflaws with different lengths under uniaxial loading," Advances in Civil Engineering, vol. 2020, Article ID 8871335, 13 pages, 2020. 